\title{
MÉTODO DOCUMENTÁRIO E A ANÁLISE DAS ORIENTAÇÕES GERACIONAIS DA JUVENTUDE
}

\author{
Breitner Luiz Tavares*
}

\begin{abstract}
Considerando a diversidade teórico-metodológica dos estudos sobre juventude no Brasil e no exterior, este trabalho faz uma apresentação geral da contribuição teórica do método documentário desenvolvido a partir de Karl Mannheim para a pesquisa qualitativa em Ciências Sociais. Dessa forma, observa-se o potencial analítico do método para o estudo das orientações coletivas promovidas pela juventude, no sentido da construção de um estilo de vida em torno da cultura jovem, como fator preponderante para a configuração geracional. Em termos empíricos, este artigo propõe a abordagem do problema referente à marginalização da juventude de comunidades localizadas na periferia urbana do Distrito Federal, tendo por referência Ceilândia. Mais precisamente, o recorte analítico é o estilo de vida em torno da cultura hip-hop praticada por jovens no Distrito Federal, compreendido como mecanismo produtor de suas orientações coletivas.

PaLAVRAS-CHAVE: Método documentário. Orientações coletivas. Juventude. Hip hop. Distrito Federal.
\end{abstract}

\section{JUVENTUDE E PESQUISA SOCIAL: alguns cenários}

Ao se remeter à categoria juventude no Brasil, objeto de diversas conotações, faz-se necessário mencionar algumas contribuições, as quais ajudarão na aproximação da configuração de um campo temático para o estudo sociológico da juventude, tais como o conceito de gerações e os estudos subculturais, entre outros, que irão mobilizar a construção de diferentes abordagens teórico-metodológicas relativas aos estudos sobre juventude.

Apesar da relevância do quadro das juventudes de classe popular, os estudos iniciais sobre sociologia da juventude no Brasil estiveram mais voltados para a classe média universitária (Ianni, 1968). Geralmente, esses estudos chegavam a conclusões em que se considerava o jovem universitário "mais politizado", ou por ter acesso a mais informação, ou pelo próprio contexto acadêmico,

* Doutor em Sociologia. Professor do Departamento de Saúde Coletiva da Universidade de Brasília (Campus Ceilândia).

QNM 14 Arrea Especial. Cep: 72220-140. Ceilândia Sul Distrito Federal - Brasil. btavares02@gmail.com. que suscita a reflexão sobre a questão política de uma maneira mais "profunda" em relação ao operário semialfabetizado das fábricas.

Marialice Foracchi (1972, p. 44), autora pioneira nos estudos sobre juventude no Brasil, traz uma série de contribuições em termos da análise dos processos de socialização e inclusão da juventude no mundo adulto, em especial sobre o jovem universitário e seu envolvimento com o movimento estudantil. Além disso, a autora demonstra como esse processo pode ser conflituoso em função da rebelião que compõe o comportamento juvenil.

De fato, os movimentos juvenis europeus e norte-americanos influenciaram as primeiras publicações sobre uma sociologia da juventude no Brasil (Brito, 1968). Os estudos de Ianni (1968) e Foracchi (1972) também corresponderam a essa tendência das juventudes dos setores médios. Nesse caso, a ênfase no movimento estudantil e na sua forma específica de organização levou à elaboração de hipóteses sobre a juventude de classe popular, que apontavam para um suposto desinteresse ou mesmo uma incapacidade de alguma mobilização de cunho político reivindicatório. 
Dessa forma, pode se considerar que os primeiros estudos sobre juventude no Brasil, até meados dos anos 70, estavam mais voltados para a análise de como os jovens se configuravam como geração numa estrutura social distribuída em termos de classe e status sociais.

Abordagens à maneira dos estudos culturais, interessadas numa etnografia das subculturas juvenis, terão maior visibilidade a partir dos anos 1980 e 1990. Durante essas décadas, foram publicados alguns trabalhos baseados na perspectiva dos estudos culturais e, por conseguinte, sobre subculturas, com destaque para algumas publicações como nos estudos sobre o movimento punk no Rio de Janeiro (Caiafa, 1985) e São Paulo (Abramo, 1994) e da cultura da festa funk, no Rio de Janeiro (Vianna, 1988). Atualmente, questões relacionadas às novas subjetividades juvenis (Almeida, 2005), a apropriações de novas mídias e tecnologias (Velho; Duarte, 2010), ou mesmo ao comportamento político da juventude em relação aos valores democráticos e movimentos sociais têm sido estudadas numa escala continental, enfocando pesquisas articuladas por diversos pesquisadores e instituições (Novaes, 2010). Essa pluralidade em termos temáticos, teóricos e metodológicos vista no cenário brasileiro reflete a capacidade de diversos pesquisadores, em diferentes tempos, de apropriação criativa de propostas, de modo a se construírem novas possibilidades de pesquisa sobre a juventude, como será considerado mais adiante em relação ao método documentário de interpretação.

\section{MÉTODO DOCUMENTÁRIOE O ESTUDO DAS ORIENTAÇÕES COLETIVAS DA JUVENTUDE}

Para o desenvolvimento da problemática sobre a cultura jovem hip-hop em Ceilândia, foram enfocados aspectos da história e da trajetória de alguns grupos de jovens que se reúnem em função do rap. A interação social dos jovens no espaço urbano foi analisada a partir do método documentário de interpretação, criado pelo sociólogo húngaro Karl Mannheim. Essa proposta terá um referencial teórico-metodológico na avaliação dos dados empíricos produzidos mediante entrevistas, observação participante, bem como a partir de produção e coleta de materiais audiovisuais, que permitem analisar aspectos de uma configuração geracional.

A identificação de uma geração é feita através da observação de laços de solidariedade, determinados em função de sua posição de classe e sua dinâmica, que, por sua vez, está associada ao ritmo biológico das sucessões de vida e morte. Os indivíduos que compartilham a mesma posição social em termos de classe e nascimento serão submetidos ao mesmo conjunto de experiências frequentes e naturalizantes da ação social condicionante de hábitos e gostos. Por outro lado, uma excessiva ênfase nos fatores econômicos da categoria "posição de classe" pode comprometer estudos sobre juventude ao não levar em conta outras dimensões da vida social que se articulam em outros níveis, como os raciais e os relacionados ao gênero. Nesse contexto, a situação geracional estabelece diferentes possibilidades para a mobilização social no âmbito político diante de diversos condicionantes como o socioeconômico de um determinado tempo.

Num determinado contexto sócio-histórico, os sujeitos sociais que pertencerem ao mesmo "grupo de idade" definirão a dinâmica de entrada e saída de novos participantes dos sistemas sociais. Essa dinâmica é determinada pelo sistema etário e limitada a um tempo histórico. Dessa forma, justifica-se a transmissão de valores a uma nova geração que se incumbirá de ressignificá-los continuamente em novos sistemas de tradição. Além disso, um indivíduo é limitado a participar de uma única configuração geracional, dada a limitação de tempo associada a suas experiências com outros indivíduos na construção de uma identidade.

La situación de clase se fundamentaba en la correlativa existencia, en la sociedad, de una estructura económica y de poder que está en transformación. Por su parte, la posición generacional (die generationslagerung) se fundamenta en la existencia del ritmo biológico en el 'ser ahí' del hombre: en los hechos de la vida y 
de la muerte y en el hecho de la edad (Mannheim, 1993, p. 208).

O método documentário de interpretação foi desenvolvido por Mannheim (1990) para a análise da categoria weltanschauung, "visão de mundo". ${ }^{1}$ Trata-se de um esforço teórico para se desenvolver uma sociologia da cultura que vai atribuir uma importante ênfase aos aspectos qualitativos das orientações coletivas dos grupos sociais. A weltanschauung resulta de "[...] uma série de vivências ou de experiências ligadas a uma mesma estrutura que, por sua vez, constitui-se como base comum das experiências que perpassam a vida em múltiplos indivíduos" (Mannheim apud Weller, 2005, p. 264).

Mannheim (1990) objetivava estabelecer um método interpretativo influenciado pela "hermenêutica romântica", produzida entre o final do século XIX e início do século XX, que distinguisse a lógica do conhecimento entre as ciências naturais e ciências humanas. Ele considerava que compreender (verstehen), para as ciências sociais e a história implicaria um "[...] trabalho de leitura da situação de análise do contexto ao qual a ação ou crença pertencem, compreendendo-as sob a ótica de outras ações e crenças historicamente construídas." (Scocuglia, 2002, p. 251). Outras abordagens de cunho compreensivo, nas ciências sociais, ocorrem na obra de autores como Max Weber, na fenomenologia de Alfred Schutz, na dramaturgia de Erving Goffman, entre outros.

Weller (2002) analisa o conceito de visão de mundo em Mannheim como instrumento para compreensão das ações dos indivíduos de um determinado grupo. As visões de mundo não podem ser construídas aleatoriamente como teorias. Dessa forma, essas práticas são constituídas a partir do conhecimento $a$-teórico. Assim, a conceitualização teórica se constitui em instrumento para a compreensão das ações coletivas que produzem esse conhecimento $a$-teórico.

1 A categoria "visão de mundo" (weltanschauung) pode eventualmente ser associada a outras expressões, como representações ou orientações coletivas.
Para o autor, as experiências do mundo da cultura devem ser entendidas a partir de categorias próprias, mas distintas da teoria como tal. Refletir teoricamente, ou seja, traduzir em teoria um fenômeno de natureza sui generis, como expressões da subjetividade de uma juventude, significa voltar-se para dimensões pré-teóricas, no nível da existência cotidiana. Nesse contexto, há uma clara tentativa de superação da dicotomia entre a reflexão de caráter eminentemente teórico e a da pesquisa, que seria simplesmente "empírica". Isso se sustenta quando se admite que a teorização não se inicia com a ciência, mas sim no âmbito da experiência cotidiana.

A teorização, pois, não começa com a ciência; a experiência quotidiana pré-científica é, portanto, recolhida com pedaços da teoria. A vida na mente é um fluxo constante, oscilando entre o polo teórico e a-teórico. Assim a teoria tem o seu lugar próprio, a sua justificação e o seu sentido mesmo no domínio da experiência imediata, concreta - no domínio a-teórico (Mannheim, 1986, p. 59).

Dessa forma, a visão de mundo como uma síntese, como meio para se traduzir representações de uma coletividade, de uma geração, é uma entidade ainda não constituída, localizada além do teórico. De outra forma, as ações sociais, como modo de expressão de múltiplos sentidos, advêm do âmbito racional, embora de natureza ateórica. A compreensão teórica dessas ações a partir da categoria de "visão de mundo" está além de todas as realizações de sentido, embora seja, de algum modo, obtida através delas. Assim, os jovens da cidade de Ceilândia, na medida de suas realizações na vida cotidiana, constroem visões de mundo a partir das ações práticas. Contudo, esses jovens se compreendem mutuamente em função da convivência pré-reflexiva, tácita, sem empregarem necessariamente uma interpretação de suas ações.

As orientações coletivas ou visões de mundo, segundo Mannheim e Foracchi (1982), derivam da experiência conjuntiva de um grupo que possui traços de generalidade. Elas são objetivas porque estabelecem o sentido para as possíveis experiências de um grupo, para além da psique individual. 
Uma orientação coletiva incorpora a situação externa à sua funcionalidade para uma comunidade em particular, no sentido que isso contém. Nem todos os indivíduos podem ler essa funcionalidade. Contudo, qualquer um pode entender suas ligações concernentes da situação original da representação coletiva junto com o sentido que isso contém. Para as mesmas razões todos os conceitos e representações coletivas possuem um caráter expressivo, assim como um sentido documentário com respeito a sujeitos individuais ou coletivos que os produzem (Mannheim; Foracchi, 1982, p. 208, tradução do autor).

Dessa forma, Mannheim e Foracchi (1982) argumentam que nenhum indivíduo num grupo comanda tudo que é conhecido, que pode já estar disponível para o grupo no que se refere à forma das partes do grupo, na sua produção de valores e conhecimento. A totalidade do que pode ser conhecido é dividida entre vários indivíduos, cada um dos quais se envolve num segmento em particular da possível representação do espaço de experimentação coletiva. Entretanto, a totalidade desses segmentos forma um todo orgânico que não existe na cabeça de ninguém como um todo, mas, de certa forma, está "suspenso" sobre o grupo. Exemplifica-se que todo culto é uma totalidade na qual cada indivíduo tem sua função e regra, mas onde a totalidade é algo que depende de si mesmo para a atualização e pluralidade de indivíduos que, nessa perspectiva, alcançam algo além de uma psique individual.

\section{Sociologia compreensivaeo método documentário}

Mannheim (1986), de fato, propõe um sofisticado sistema para sua metodologia hermenêutica, vinculado à perspectiva de uma sociologia compreensiva. Nele, são estipulados três aspectos a serem considerados no processo de interpretação do sentido das ações sociais. Quer dizer, a observação se torna viável ao se considerar que as ações sociais revelam três "estratos de sentido": o objetivo, o expressivo e o documentário. Para Mannheim (1986), os fenômenos da cultura só podem ser compreendidos plenamente se observados como uma coisa em si mesma.

A tripla diferenciação dos estratos de senti- do da "visão de mundo" será considerada no contexto dos grupos juvenis vinculados ao hip-hop em Brasília. Isso será viável a partir do momento em que a configuração social for conhecida por meio da observação. O conhecimento da configuração objetiva será fundamental para que se oriente o processo de compreensão dos significados construídos por essa juventude, na medida em que ocorrerá a interação do pesquisador no ambiente onde são construídas essas significações.

Quando se está diante de interlocutores ou de um bem simbólico, como uma letra de música, é possível que haja intencionalidades distintas daquelas apresentadas no primeiro contato observado no nível objetivo. Assim, para além do significado objetivo, o ato observado poderá conter um significado inesperado, às vezes até contraditório. Nesse caso, o observador terá de recorrer a novas categorias para aquilo que se apresenta de maneira dinâmica para além de sua mera "aparência”; para cada significado novo será necessária uma categoria nova, capaz de explicar a expressividade da ação definida pelos sujeitos sociais.

O significado expressivo é relevante, pois permite observar o sentido íntimo que os indivíduos atribuem a suas ações, sem separá-los do mundo da experiência. Dessa forma, o estilo musical rap permite a construção de todo um meio expressivo por parte de seus interlocutores, que fazem alusão a categorias como a pobreza, a vida na periferia urbana ou a sua identidade racial. $O$ observador deve perceber esse "universo íntimo" em um primeiro momento, a partir do sentido atribuído por esses jovens.

\begin{abstract}
Este conteúdo expressivo, apesar do fato de não possuirmos dele um conhecimento teórico-refletido, mas somente uma experiência direta, concreta, pré-teórica, é ainda significante, isto é, de alguma forma interpretável, mais do que algo meramente físico, um estado difusamente endurecido. Pode-se compreender o significado das ações pela interpretação sem recorrer-se ao que é subjetivamente pretendido (Mannheim, 1986, p. 67).
\end{abstract}

Segundo o autor, o pesquisador, ao se posicionar como "testemunha" que observa e interpreta a cena, está em condições de partir do sig- 
nificado expressivo para o significado documentário, que se refere à compreensão daquilo que é expresso pelos indivíduos de modo inconsciente, não intencional. No caso em que se pretende documentar as representações coletivas de jovens, é relevante atentar-se, inclusive, para aspectos não verbais, como gestos, expressões faciais, o modo de conversar. Isso porque, enquanto ocorre uma conversa entre jovens e pesquisador, em alguns casos, o pesquisador pode perceber ou constatar a assimetria entre o que é dito e o que é expresso, tanto no jogo corporal como no contato ambiental do lugar. A observação desses múltiplos aspectos expressivos dos jovens permitirá ao pesquisador uma visão mais abrangente da ação social. Isso se torna relevante para se promover uma análise documentária, ou seja, para que se compreenda a ação social além da intencionalidade dos atores sociais.

Uma reconstrução desse nível documentário parte do sentido da ação no contexto em que ela ocorre e em que está inserida. Trata-se daquilo que foi denominado por Bohnsack (apud Weller, 2005) como observação de segunda ordem, o acesso ao conhecimento pré-reflexivo dessa juventude. Como considera Weller (2005), essa reconstrução interpretativa parte de algumas questões estipuladas diante do nível objetivo das representações dos sujeitos sociais.

Nessa etapa de reconstrução documentária, o pesquisador deve analisar que determinados sinais de linguagem inscritos em gestos estereotipados não encerram simplesmente uma "gramática universal". A atenção, nesse caso, deve estar voltada para outros possíveis gestos que possuam uma carga expressivo-significativa para os jovens. Contudo, observar a expressividade de gestos individuais não implica meramente uma abordagem psicológica das representações da juventude. De fato, o nível de interpretação documentária parte da experiência psíquica dessa juventude. O sentido documentário não demanda, necessariamente, conhecer toda a trajetória dos indivíduos, para que se possa compreendê-los num determinado contexto das representações coletivas.

Oque sefaz relevante, nosentido documentário, não é explicar o que significa o hip-hop em termos essenciais, mas compreender como se opera a construção de identidades; como, a partir do hip-hop, uma juventude como a localizada na cidade de Ceilândia orienta suas práticas sociais. A maneira como os assuntos são tratados em uma conversa, bem como o tipo de seleção dada a esses assuntos, em determinado contexto, pode ser mais uma pista para a construção desse sentido compreensivo.

Weller (2005, p. 270) considera que, no âmbito analítico, a postura sociogenética do pesquisador corresponde a colocar "entre parênteses o caráter de validade dos fatos sociais". A vontade de verdade reivindicada pelo discurso do informante, sua índole, não podem, nesse caso, ser um fator impeditivo para o questionamento do pesquisador sobre as falas apresentadas pelos entrevistados em relação às suas práticas sociais.

O sentido documentário, diferentemente do sentido expressivo, pode recorrer a aspectos parciais da representação coletiva, tais como depoimentos de jovens sobre suas ações ou mesmo informações de outra natureza, como documentos produzidos anteriormente sobre essas ações, como letras de música. Informações parciais podem contribuir para a reconstrução das orientações coletivas em termos documentários. Dessa forma, a interpretação documentária da juventude em Ceilândia é influenciada pelo seu contexto, pela sua localização histórica sociogenética. Essa condição demanda ainda uma contínua renovação da interpretação documentária. A tradução, em termos teóricos, desse conjunto de significações da vida cotidiana ateórica ocorrerá mediante certos aspectos significativos que prevalecem em relação a outros.

Ainda em relação às influências sobre a representatividade da interpretação, está em jogo a posição ocupada pelo pesquisador, que tem uma afiliação teórica. O lugar de onde fala não corresponde à neutralidade. As experiências cotidianas, bem como o reconhecimento de uma posição de classe, raça, gênero, entre outras, não se excluem num processo de análise. Em relação ao aspecto da objetividade, Bohnsack (apud Weller, 2005) propõe que o método comparativo dos da- 
dos seja uma forma de controle dessas subjetividades. Dito de outra forma, a reconstrução teórica do conhecimento a-teórico se dá pela perspectiva comparativa de outros casos, o que acaba por deixar em segundo plano o "conhecimento teórico do pesquisador".

A análise comparativa desempenha, assim, um papel de controle metodológico da compreensão da realidade estranha ou distante do universo do(a) pesquisador(a) - 'methodisch kontrolliertes remdverstehen' -, ou seja, de controle das afirmações ou generalizações realizadas sobre a realidade observada (Weller, 2005, p. 23).

Na pesquisa sobre jovens do Distrito Federal, foram realizados grupos de discussões. Esse método de abordagem foi difundido pelos integrantes da Escola de Frankfurt nos anos 50 do século passado, principalmente por Pollok (1955 apud Weller, 2006). Mais adiante, nos anos 70, recebe influências teóricas do interacionismo simbólico, da fenomenologia e da etnometodologia. A abordagem teórica dessa técnica de pesquisa eleva o status dos grupos de discussão para um método de pesquisa.

Mangold e Bohnsack (apud Weller, 2006) consideram que os grupos, ao se posicionarem perante certas questões trazidas pelo pesquisador, não formulam suas respostas simplesmente pela ocasião de uma interação; essas opiniões constituem reflexos das orientações coletivas ou visões de mundo referentes ao contexto social dos entrevistados. Nesse caso, torna-se relevante conhecer vivências coletivas dos jovens. Portanto, a noção sociológica de grupo é definida pela relação de interdependência, na qual se compartilham valores numa dinâmica que, eventualmente, enfatiza aspectos harmônicos ou conflitantes, que são intrínsecos a um grupo estruturado (Vandenberghe, 2005 , p. 115). De fato, na medida em que as regras e os costumes compartilhados por um grupo se tornam peculiares, observa-se sua relativa separação de outros grupos sociais em função do estilo de vida.

O método de pesquisa dos grupos de discussão, segundo Ralf Bohnsack (1989, 1999, 2004, apud Weller, 2006), permite observar aspectos es- truturais da sociedade. Estes "modelos" são orientadores das experiências individuais e coletivas num determinado meio social, como é o caso da juventude. Isso, associado à perspectiva do método documentário de interpretação de Mannheim (1990), permite dois modos de observação: um "interno", relacionado ao sentido da ação atribuída a partir dos indivíduos no contexto de sua interação, e outro "externo," orientado para a representação das interações num contexto estrutural.

Ao ser retomado nos anos 80, o método dos grupos de discussão passou a ser empregado especialmente em pesquisas sobre juventude. Os enfoques dessas pesquisas eram variados. Havia interesse em estudos sobre desenvolvimento, gerações, formação educacional, gênero, meio social, entre outras tipologias.

Nesse sentido, o método de grupos de discussão será relevante para que o pesquisador se aproxime do contexto relacional dessa juventude ceilandense, expresso através de seus discursos e gestos, de modo que se possam reconstruir, teoricamente, aspectos do seu meio social, histórias e trajetórias desses grupos e o enfrentamento do racismo no contexto de uma segregação socioespacial imposta pela lógica urbana do Distrito Federal. Será enfatizada a análise do habitus dos grupos hiphop, com enfoque em sua manifestação social resultante da condição geracional dessa juventude.

Para a operacionalização das entrevistas no método de grupo de discussões, foi produzido um tópico-guia que tem a finalidade de combinar certas leituras relevantes com a temática da juventude hip-hop em Ceilândia. Esse tópico-guia é resultante de conversações preliminares com sujeitos sociais relevantes e tem a função de organizar o encaminhamento do grupo de discussão, bem como das informações obtidas nesse contexto.

As perguntas apresentadas em seu corpo foram direcionadas para as representações sociais; pergunta-se sempre "como" as ações se constituem. Essas perguntas têm a finalidade de se constituir em um ponto inicial para a construção das falas. As terminologias empregadas são simples e direcionadas para as práticas cotidianas de jovens 
que, em muitos casos, não tiveram acesso à escolarização.

A flexibilidade é um fator importante nesse tipo de planejamento, uma vez que muitas questões, às vezes, complexas, no contexto da entrevista, podem se tornar secundárias ou irrelevantes. Esse tópico-guia, de fato, estará sujeito a inovações em função das situações vivenciadas no contexto de sua aplicação. Por outro lado, a análise das orientações coletivas dos grupos não seguiu necessariamente a sequência das questões elaboradas. Portanto, as mudanças e situações novas devem sempre ser registradas. Também será aplicado um questionário com o objetivo de se ter acesso a mais informações complementares das trajetórias histórico-biográficas dos entrevistados.

Em relação à quantidade de entrevistas a serem produzidas numa pesquisa de cunho qualitativo, alguns aspectos que a caracterizam devem ser considerados. Em primeiro lugar, a seleção das entrevistas, diferentemente de uma pesquisa amostral quantitativa, está voltada para a descoberta de uma variedade de posicionamentos frente a uma questão. No método documentário de interpretação, a análise das interpretações, ou versões da realidade, mesmo que as experiências pareçam únicas nas mentes dos indivíduos, será, em termos estruturais, resultado de processos sociais. Num primeiro momento, elas são surpreendentes; posteriormente, temas comuns começam a surgir, e as surpresas tornam-se mais infrequentes em função do processo comparativo dos dados.

Durante a pesquisa, foram realizados quinze grupos de discussão com aproximadamente cinquenta e cinco jovens, organizados em grupos de rap e street dance. Os jovens, em geral, identificavam-se com o hip-hop e com os grupos dos quais fazem parte. Em geral, estavam habituados a realizar apresentações públicas em escolas, casas de festas ou boates.

Em relação aos aspectos metodológicos, a interpretação documentária permite compreender, a partir do hip-hop e suas manifestações artísticas, a música a partir dos sentidos das ações coletivas produzidas por esses grupos jovens em suas nar- rativas, bem como permite observar as representações sociais no gestual, naquilo não aparece na forma textual, escrita, mas que está imanente à ação. Dito de outra forma, trata-se de observar para além do conteúdo textual das falas apresentadas e se voltar para outro nível de sentido, expresso de maneira não verbal, ou seja, através dos gestos articulados.

Em relação ao critério de seleção dos grupos, levou-se em conta a qualidade das respostas apresentadas durante as discussões dos grupos, obtida a partir da demonstração do seu conhecimento sobre as questões apresentadas, como discute a teoria fundamentada ou ground theory (Glaser; Strauss, 1967).

Durante o trabalho de campo, a cada entrevista, era feita uma avaliação em relação aos grupos entrevistados, de modo a construir uma amostra representativa em função dos interesses teóricos da pesquisa. Nesse caso, foram selecionados quatro grupos de jovens que se reúnem pelo interesse musical no rap. Essa seleção permite submeter as informações apresentadas por cada grupo a uma comparação com outras entrevistas realizadas anteriormente, de modo a verificar a pertinência das questões de pesquisa, bem como a análise das orientações coletivas dos jovens expostas durante as respostas explicitadas na realização dos grupos de discussão. Essa abordagem está vinculada à perspectiva da amostragem teórica proposta por Glasser e Strauss (1967).

Além disso, os grupos apresentaram, em suas respostas, aspectos que permitiram a análise comparativa de suas orientações coletivas em torno da formação geracional, relacionamento e sexualidade, bem como em torno de suas experiências frente à discriminação. Apesar de algumas exceções, os jovens, em geral, têm entre 17 e 27 anos, são homens, identificam-se como negros e vivem nos setores considerados mais pobres em Ceilândia. Os procedimentos de coleta de dados por meio da observação participante, bem como a ênfase na história de vida dos atores sociais entrevistados, foram utilizados para se reconstruírem as visões de mundo presentes em suas ações coletivas. Nesse caso, o método documentário de inter- 
pretação encontra operacionalidade de diversas formas. Materiais como imagens fotográficas, documentos e a prática da observação participante, incluindo-se a realização de entrevistas, podem constituir referenciais para o processo de compreensão da visão de mundo dos sujeitos sociais. Essa triangulação de métodos ou de técnicas de coleta de dados será de grande relevância para uma maior abrangência da análise das entrevistas de grupo.

Em atenção a aspectos éticos, os nomes dos respondentes, bem como o nome dos setores onde vivem, grupos e organizações, receberam pseudônimos com vistas a garantir o anonimato, bem como para preservar sua integridade.

ORIENTAÇÕES COLETIVAS E GERACIONAIS: estilo de vida hip-hop e o envolvimento com trabalho social

Para a construção de um tipo analítico das orientações coletivas dos grupos selecionados, foram enfocados aspectos relacionados às questões da estrutura familiar na região onde vivem. Esse enfoque permitiu que se observasse como a família e as relações interpessoais de amizade são relevantes para a construção de um sentido de pertencimento, observado a partir das orientações coletivas dos jovens em torno do estilo hip-hop, em especial pela apreciação do rap como forma de expressão estética. O espaço urbano em sua complexidade bem como as semelhanças no que se refere à condição de classe dos grupos permitiram que os jovens se identificassem numa experiência intersubjetiva geracional.

As orientações coletivas em relação ao estilo hip-hop revelam que, em geral, os grupos tentam definir sua identidade em oposição a outros grupos. Isso ocorre a partir da indumentária, que constrói um corpo com seus aparatos e gestos, além de um discurso no sentido de um movimento de protesto e denúncia, que caracteriza o sentido de "missão" que esses grupos pretendem para suas ações. Os jovens, em diversos momentos, voltamse para estereótipos criados por eles como meios distintivos de outros grupos subculturais, como "pagodeiros" ou "roqueiros". Contudo, informalmente, observa-se que, nos espaços de sociabilidade, como em escolas, festas ou no setor onde vivem, esses jovens rappers interagem com outros grupos e estabelecem vínculos de socialização que ultrapassam o sentido sectário observado em alguns momentos de seu discurso.

O sentido das orientações coletivas dos grupos de jovens envolvidos com o rap se situa no contexto comparativo realizado entre outros grupos selecionados. Os resultados encontrados sobre suas orientações geracionais, portanto, correspondem à sua visão de mundo frente a questões relativas às suas práticas culturais em relação à musicalidade do rap e outros componentes do hip-hop. As respostas relacionadas às orientações geracionais dos jovens rappers, apesar de serem definidoras de seus próprios estilos de vida, por outro lado, não constituem algo que seja necessariamente exclusivo desse tipo de subcultura. Em outros termos, grupos de jovens envolvidos com o samba ou o rock podem apresentar elementos comparativamente semelhantes às orientações coletivas de jovens rappers, apesar da diferença expressa pela superficialidade de sua indumentária.

Os grupos de rap apresentaram diversas semelhanças, o que não implica um caráter homogêneo no que se refere à sua formação e envolvimento com o rap. As relações vicinais estruturadas pela escola e pelas limitações geográficas que os bairros impuseram foram decisivas para a realização de um encontro dos jovens. Há um protagonismo jovem que chama a atenção para um envolvimento no sentido da mudança social em suas vizinhanças e famílias. Os jovens buscam assumir a responsabilidade por aquilo que, às vezes, chamam de "revolução", ou "correr atrás de algo verdadeiro". Além disso, o ambiente familiar se configurou como um espaço relativamente importante para a socialização e contato com gerações mais velhas, representadas pelos pais, mães, padrastos ou irmãos de modo intergeracional. Contudo, apesar da ênfase dada à família e ao respeito aos mais velhos, esse tipo de argumento paralela- 
mente informava o desejo e as atitudes dos jovens no sentido de construção de um contexto geracional específico, de um espaço paralelo ao mundo adulto, no qual eles pudessem construir sua identidade a partir do seu estilo de vida, com suas respostas aos problemas enfrentados em seu cotidiano.

Sobre a formação dos grupos, o BR45 e o Rap Comando se originaram de maneira semelhante, ambos a partir de projetos promovidos por instituições assistenciais que atuam em escolas no setor QNZ, onde os jovens residem. Os membros do grupo BR45, formado há mais de dez anos, frequentaram esse tipo de oficina até decidirem deixar o ambiente da escola para atuarem como artistas locais representantes do estilo rap. O Rap Comando, por sua vez, é um grupo formado recentemente, há seis meses, e ainda frequenta o espaço das oficinas como uma possibilidade de se encontrar nas vizinhanças, bem como uma forma de aprender aspectos técnicos que envolvem o rap e o grafite como estéticas do hip-hop importantes para o grupo.

Contrariamente, os grupos Revolução MCs e Resistência Periférica surgiram da relação vicinal entre jovens que se encontravam nas redondezas do setor onde vivem, em quadras esportivas, jogando futebol ou em bailes. Eles compartilham das mesmas experiências que os motivaram a criar o grupo. Diferentemente dos jovens do BR45 ou do Rap Comando, o Revolução MCs e o Resistência Periférica não foram produzidos no interior de programas assistenciais ou ONGs, mas a partir da iniciativa de grupos de afinidade, que passaram a agir como jovens empreendedores locais e que compartilhavam das mesmas situações existenciais de pobreza e exclusão social. Todo o processo de desenvolvimento desses grupos, passando pela elaboração de um nome representativo, bem como pelo tipo de letras que iriam abordar, dentre outros aspectos da formação de um sistema de gostos expressos por suas orientações coletivas, está associado ao processo de autoaprendizagem a que os grupos se submeteram na busca de uma identidade em comum e de determinados fins para sua práxis estética.

Em relação à elaboração de um projeto político-pedagógico, os grupos estão voltados para um conjunto de práticas lúdicas e consumo de bens identificadores com os sentidos de uma missão transformadora. Diante disso, o grupo BR45 discute seu processo de formação seletiva, em que muitos não resistiram devido ao envolvimento com o uso de drogas e a pichação, prática contrária à ética do grupo. Criar um grupo de rap foi o meio encontrado por esses jovens para apresentar um contraponto, uma aposta num futuro livre desses problemas. Além disso, o envolvimento com o rap e com a capoeira permitiu ao grupo se reconhecer como um produtor de "cultura" no sentido de um conjunto de práticas identificadoras de uma negritude.

Os jovens do Rap Comando argumentam que o rap é uma forma de expressão artística e política dos problemas que enfrentam em sua cidade. $\mathrm{O}$ sentido de mudança social, para esses jovens, se expressa, como já antecipado, no sentido de "correr atrás" de algo "verdadeiro". A crônica social elaborada nas letras do grupo representa um meio de organização e mobilização locais pelas mudanças que julgam necessárias para superar os constrangimentos sociais, definidos como as "humilhações".

O grupo Revolução MCs, de modo semelhante ao grupo BR45, reivindica o sentido de uma missão política para realizar o resgate daqueles envolvidos no "vício do álcool e das drogas". O meio para essa mudança de atitude está relacionado ao potencial lúdico e atrativo que o hip-hop apresenta para a juventude. O rap, como uma forma política de identidade, adquire uma conotação mais efetiva em termos de sua capacidade de transformação quando associado à conversão religiosa protestante. A orientação religiosa redefine os vínculos afetivos de amizade entre os jovens e suas famílias, o que gera a capacidade de mobilização social para lograr suas finalidades políticas de "resgate social".

Ogrupo Resistência Periférica enfatiza as trajetórias familiares de seus integrantes, bem como de outros jovens que compartilham das mesmas condições de violência enfrentadas no setor da cidade simplesmente denominado como QNX. O enfrentamento desses problemas seria o eixo norteador de uma formação geracional em relação ao hip-hop e ao rap, com vistas a criar uma repre- 
sentação política a partir de manifestações estéticas.

Em geral, o sentido de missão política voltada para a mudança social assumida pelos grupos - apresentada de diversas maneiras, tais como "revolução”, "cultura forte”, "buscar algo verdadeiro”, entre outras - não passa pela perspectiva dos movimentos sociais político-partidários ou de uma esquerda política institucional, com ideais revolucionários tradicionais. De fato, os jovens se organizam de modo autônomo e defendem uma intervenção de natureza assistencialista através de ONGs nas regiões onde vivem, com um meio ambiente urbano desprovido de equipamentos públicos voltados para o lazer e programas sociais para a juventude.

Em relação à visão do espaço social urbano, os jovens dos grupos denunciam que, mesmo em sua região, os valores individualistas prevalecem em detrimento de valores associativistas e comunitários. Mesmo vivendo em meio a um setor desprovido de infraestrutura e falta de lazer, as pessoas estão mais preocupadas em "andarem bonitinhas”. Os grupos defendem uma intervenção no sentido de se garantir o direito à cidade por práticas lúdicas de lazer e esportes. Essa seria a garantia de uma redução do quadro de violência nas cidades onde vivem.

Os jovens dos grupos, em geral, defendem um protagonismo jovem, em que o rapper assumiria o caráter formal de uma liderança comunitária no sentido de defesa dos interesses locais. Essa prática se daria pelo rap como uma forma de veiculação de protesto e engajamento em defesa dos jovens, como foi mencionado na expressão do grupo Resistência Periférica: "ser os advogados dos moleques". O sucesso como empreendedores musicais também deveria ser consequência da criação de uma nova cultura política. Por outro lado, os grupos reconhecem a dificuldade de se alcançar o ideal de uma transformação frente a valores que primam por relações mais impessoais e individualistas, mesmo na periferia da metrópole.

Em relação à percepção do espaço urbano e de possíveis interações sociais, os grupos descrevem os valores que são predominantes numa peri- feria em duas diferentes abordagens. Em relação à primeira, de tom pessimista, os jovens afirmam que os desacertos ou rixas são frequentes como forma da materialização da violência que atinge, principalmente, os jovens em seu cotidiano na escola, nos campos de futebol, na esquina, nos bailes, entre outros. A violência entre jovens é naturalizada como parte da rotina cotidiana, base para o discurso de "resgate" social. Existe uma mitificação dessa representação social da violência a partir de estereótipos urbanos, onde há criminosos e policiais corruptos, de um lado, e a população refém de um estado de descontrole social, de outro. Em relação à segunda abordagem, ela está relacionada a uma mobilização, “correr atrás” ou "ser os advogados dos moleques", o que se relaciona ao item discutido anteriormente sobre protagonismo jovem e sentido de mudança social. Em geral, os jovens enfrentam grande dificuldade para realizar seus projetos como produtores locais e como lideranças políticas em potencial.

Em relação ao enfrentamento de uma perspectiva urbana e distópica materializada, definida pela violência, os grupos defendem uma reelaboração das regras sociais, em que a humildade e o sentido de existência do grupo passam a ser parte da etiqueta urbana. Para isso, cria-se um conjunto de gestos, o que seria um atributo do estilo rap, uma estratégia jovem de sobrevivência, que é materializada corporalmente pelo vestuário característico do estilo hip-hop.

Durante as discussões com os grupos de rap, ao apresentarem suas queixas sobre os problemas locais, como pobreza e violência, bem como ao falarem da dificuldade para uma mobilização social, os jovens construíram uma categoria de alteridade que seria, em parte, responsável pela dificuldade na mudança social que vislumbram. Trata-se da categoria playboy, às vezes denominada, "riquim" (riquinho), que é utilizada para tratar do outsider, ou seja, daquele jovem que não compartilha o mesmo status social dos jovens que vivem na periferia como parte de um sistema classificatório. Segundo eles, o playboy não reconhece as regras locais e ostenta um suposto privi- 
légio de classe e eventualmente se envolve em conflitos com os jovens da periferia, "os humildes".

Sobre a relação dos grupos com pessoas mais velhas, ou seja, que pertencem a diferentes gerações, os grupos apresentam respostas aproximadas. A relação com pessoas mais velhas é sempre considerada como importante, especialmente no que diz respeito ao acesso à experiência acumulada durante os processos socializadores. Por outro lado, também se observa, nos dois grupos, a tendência a buscar espaços de circulação e de troca de experiências que sejam exclusivamente jovens. A relação entre diferentes enteléquias geracionais, ou seja, diferentes construções do sentido de visão de mundo, como no caso dos rappers e seus pais, está condicionada a uma abertura para o reconhecimento das alteridades, baseada naquilo que os jovens definem como "respeitar para ser respeitado".

Sobre a relação familiar, a mãe é representada como alguém de extrema importância, principalmente em se tratando de famílias cujos pais estão ausentes. A idealização do pai, às vezes, passa por uma extrema depreciação, especialmente quando ele é ausente da família. Contudo, mesmo nesses casos, o sentido do pai como patriarca, provedor, prevalece: trata-se do pai "guerreiro". O relacionamento entre irmãos e irmãs está condicionado a padrões hierárquicos tradicionais, em que se valoriza o mais velho e o sexo masculino como corresponsável pela educação dos mais jovens. Todavia, observam-se certas limitações, em que os mais jovens e as meninas subvertem esse legado patriarcal. Em alguns casos, os irmãos mais velhos são apresentados como referenciais para a socialização dos jovens no hip-hop, ou são construídos como "heróis" que protegem seus irmãos mais novos do envolvimento com a delinquência.

Em termos da constituição dos grupos como uma subcultura, os jovens entrevistados expressaram estar vinculados a um determinado padrão de gosto social que envolve a apreciação pela indumentária hip-hop e passa por um modo de se vestir distinto de outros estilos jovens, assim como um gosto musical pelo rap. Os jovens desses grupos, apesar de manifestarem, em algum momento, uma posição sectária em relação a outros estilos, como o "pagodeiro" ou o "roqueiro", em conversas informais, admitiram frequentar outros espaços, onde circulam outros tipos de jovens, como os shoppings, definidos como espaço dos jovens "playboys". Portanto, isso deixa implícito que uma identidade como a de uma subcultura é menos restrita do que se poderia supor. Apesar de os jovens elegerem um discurso de "missão", em termos de envolvimento nas atividades sociopolíticas em suas comunidades, eles eventualmente se envolvem com outros grupos, como os de jovens que apreciam o pagode, o forró, ou outros ritmos tocados em bares nas redondezas. Esses jovens, de outra maneira, não trazem nenhum discurso "revolucionário", típico do hip-hop, mas abordam, por outro lado, o hedonismo e o amor romântico, temáticas pouco comuns nas letras dos grupos de rap nacional, que, em geral, tratam de problemas sociais na forma de um "protesto cantado". Portanto, os grupos de rap transitam entre outros jovens, mas demarcam seus referenciais a partir de um conjunto de elementos estéticos que compõem o hip-hop.

\section{CONSIDERAÇÕES FINAIS}

Apesar da pouca utilização do conceito de gerações por pesquisadores brasileiros, assim como da variável metodológica do método documentário de interpretação e dos grupos de discussão, há algumas pesquisadoras que têm demonstrado sua eficácia em abordagens em que há uma maior ênfase na produção de dados qualitativos (Sposito, 1994; Dayrell, 2005; Weller, 2011), e que divergem de algumas abordagens mais tradicionais, baseadas em certas hipóteses sobre a juventude, e ainda reforçam estereótipos sobre um suposto caráter da marginalidade juvenil intrínseca, assim como abordagens que tentam qualificar a juventude simplesmente por aspectos cronológicos. Essas perspectivas são facilmente encontradas em textos de autores estrutural-funcionalistas como Parsons (1942) e Merton (1968).

As múltiplas culturas jovens desafiam os 
pesquisadores a construírem um "campo de pesquisa” sobre juventude. Para enfrentar tal situação, requer-se a construção de uma metodologia explicativa desses fenômenos, presentes nas orientações coletivas juvenis, que considere aspectos relacionados ao consumo da juventude pobre das classes trabalhadoras, bem como as dimensões relativas à construção de um sistema de distinções sociais pautado em categorias como raça-etnia, gênero e sexualidade.

Diferentemente daquilo que algumas perspectivas homogeneizantes poderiam apresentar, nessa investigação sobre os jovens em Ceilândia, foi encontrada uma diversidade dentro das "culturas juvenis" (Feixa, 1999). Diante disso, diversas orientações coletivas puderam ser documentadas durante o convívio com os grupos, bem como por meio da análise dos grupos de discussões realizados ao longo da pesquisa.

O estudo das orientações coletivas em relação às narrativas de jovens negros da periferia de Brasília, em Ceilândia, enfrentou a questão da marginalização urbana a partir de suas próprias experiências. Para isso, o estudo sobre os estilos de vida, definido a partir de sua complexidade dentro de um sistema de gostos e distinções sociais, estipula toda uma rede de relações que extrapolam o grupo em si.

Essa forma de cultura popular engajada em discursos de uma "missão transformadora" foi uma referência motivadora do envolvimento das primeiras gerações de jovens no hip-hop no Distrito Federal. Isso foi realizado mediante a intervenção no espaço público através de shows, assim como no campo publicitário dos meios de comunicação, que estigmatizavam a cidade, bem como sua juventude. Nesse caso, o rap passou a ser um dos referenciais do reconhecimento da juventude antirracista na periferia de Brasília.

A análise das orientações coletivas dos jovens envolvidos com o hip-hop e o rap em Ceilândia permitiu, por meio do método documentário, construir um tipo em relação social frente à sua posição geracional e ao seu estilo cultural. A cidade, com sua complexidade e con- trastes, assim como com semelhanças no que se refere à condição de classe dos grupos, permitiu que eles se identificassem dentro de uma experiência intersubjetiva geracional.

Em relação à constituição dos grupos, eles se originaram de maneira diversa, seja a partir de projetos promovidos por instituições assistenciais que atuam em escolas no setor onde os jovens residem, seja a partir dos vínculos de amizade no contexto do setor da cidade onde residem e estabelecem formas de sociabilidade em torno do estilo juvenil.

A formação e o envolvimento dos jovens, negros em sua maioria, do sexo masculino, com idade aproximada de 15 a 25 anos, com o hip-hop e o rap, foram motivados por vários elementos, como as relações vicinais articuladas por espaços de circulação e convivência, como a escola. Contudo, apesar das semelhanças entre os jovens, isso não implica que eles sejam homogêneos, mas que compartilham de uma visão de mundo em que se elege um "protagonismo jovem" como valor. Alguns grupos estão envolvidos em trabalhos sociais coordenados por ONGs locais ou regionais, outros atuam como empreendedores de pequenas atividades voltadas para o lazer em suas comunidades.

A família, como instituição social, mostrouse relevante para os jovens que, em sua maioria, vivem com pais ou avós, os quais são espectadores do envolvimento dos seus filhos com a música. Paralelamente ao discurso que valoriza a interconexão geracional com os pais e as pessoas mais velhas, há um conjunto de assertivas que indicam o interesse dos jovens em criar um espaço de convívio restrito às suas práticas sociais em torno da música e da troca de experiências com outros jovens envolvidos num mesmo contexto geracional.

Parte da motivação dos grupos de rap em relação a uma transformação, definida por "revolução", ou "correr atrás de algo verdadeiro", traduz o sentido de vários dilemas enfrentados pelos jovens no setor da cidade onde vivem e, também, lidam com experiências discriminatórias nas escolas ou mesmo nas ruas. Apesar do desejo de mudança e mobilização local, observa-se a tensão entre valores de cunho mais individualista, repre- 
sentados pela categoria playboy, em contraposição ao associativismo preconizado pelos jovens rappers. Os desacertos e a dificuldade de mobilização, no sentido reivindicatório, levam à criação de um imaginário distópico em relação à vida na periferia urbana, além da criação de estereótipos relacionados à violência juvenil. Portanto, em suas narrativas, há uma ambivalência entre uma violência naturalizada e o discurso em torno de um resgate social a partir de uma juventude envolvida no estilo hip-hop.

Recebido para publicação em 24 de setembro de 2010 Aceito em 21 de setembro de 2011

\section{REFERÊNCIAS}

ABRAMO, Helena W. Considerações sobre a tematização social da juventude no Brasil. Revista Brasileira de Educação, Rio de Janeiro, n. 5/6, p. 25-36, maio/dez., 1997. Disponível em: www.anped.org.br/rbe/rbedigital/RBDE05 6/ RBDE05_6_05_HELENA_WENDEL_ABRAMO.pdf. Acēsso em: $2 \overline{6}$ nov. 2012 .

Cenas juvenis: punks e darks no espetáculo urbano. São Paulo: Página Aberta, 1994.

ALMEIDA, Maria I. M. Afetos, corpos e olhares: dois exercícios em torno de novas dinâmicas subjetivas nas culturas jovens contemporâneas. Eco-pós, Rio de Janeiro, v. 8, n. 1, p. 73-85, 2005.

BRITO, Sulamita (Org.). Sociologia da juventude I: da Europa de Marx à America Latina de hoje. Rio de Janeiro: Zahar, 1968.

CAIAFA, Janice. Movimento punk na cidade: a invasão dos bandos sub. Rio de Janeiro: J. Zahar, 1985.

DAYRELL, Juarez. A música entra em cena: o rap e o funk na socialização da juventude. Belo Horizonte: Editora UFMG, 2005 .

FEIXA, Carles. De jóvenes, bandas y tribus: antropología de la juventud. Barcelona: Editorial Ariel, 1999.

FORACCHI, Marialice. Juventude na sociedade moderna. São Paulo: Pioneira, 1972.

GLASER, Barney; STRAUSS, Anselm. The discovery of ground theory, strategies for qualitative research. Chicago: Aldine Publishing Company, 1967.

IANNI, O. O jovem radical. In: BRITO, Sulamita (Org.) Sociologia da juventude I: da Europa de Marx à America Latina de hoje. Rio de Janeiro: Zahar, 1968. p. 225-242.

MANNHEIM, Karl; FORACCHI, Marialice M. Kar mannheim: Sociologia. São Paulo: Ática, 1982.

O problema das gerações. In Sociologia do conhecimento. Lisboa: RES,1986. v. 1 . Sociologia do conhecimento. Lisboa: RÉS,1986. v. 2. El problema de las generaciones. Revista española de investigaciones sociológicas - REIS, Madri, n. 62, p.
123-132, abr./jun., 1993.

MERTON, K. Robert. Social theory and social structure. Ed. enlarged. The Free Press: New York, 1968.

NOVAES, Regina R. Juventude, exclusão e inclusão social: aspectos e controvérsias de um debate em curso. In: FREITAS, Maria V.; PAPA, Fernanda, de C. Políticas públicas: juventude em pauta. São Paulo: Cortez: Ação educativa: Fundação Friedrich Ebert, 2003.

; RIBEIRO, Eliane; SILVA, Itamar et al. (Org.) Livro das juventudes sul-americanas. 22. ed. Rio de Janeiro: IBASE, 2010. v. 1.

NUNES, Brasilmar F. Consumo e identidade no meio juvenil: considerações a partir de uma área popular do Distrito Federal. Soc. estado, Brasília, v. 22, n. 3, p. 647-678, set./dez., 2007. Disponível em: www.scielo.br/pdf/se/ v22n3/07.pdf. Acesso em: 26 nov. 2012.

PAIS, José Machado. Ganchos, tachos e biscates: jovens, trabalho e futuro. Porto: Âmbar, 2005.

PARSONS, Talcott. Age and sex in the social structure of USA. American Sociological Review, Washington, v. 7,n. 5, p. 604-616, out., 1942.

SCOCUGLIA, Jovanka B. C. A hermenêutica de Wilheim Dilthey e a reflexão epistemológica nas ciências humanas contemporâneas. Soc. estado, Brasília, v. 17, n. 2, p. 249281, jul./dez., 2002. (Dossiê Temático: Inovações no Campo da Metodologia das Ciências Sociais). Disponível em: www.scielo.br/pdf/se/v17n2/v17n2a03.pdf. Acesso em: 3 dez. 2012.

SPOSITO, Marília P. A sociabilidade juvenil e a rua: novos conflitos e ação coletiva na cidade. Tempo Social - Rev. Sociol. USP, São Paulo, v. 5, n. 1-2, p. 161-178, 1994 Disponível em: www.fflch.usp.br/sociologia/temposocial/ pdf/vol05n12/Sociabilidade.pdf. Acesso em: 26 nov. 2012.

TOOP, David. The rap attack: African jive to New York Hip Hop. Boston: South End Press, 1992.

VANDENBERGHE, Fréderic. As sociologias de Georg Simmel. São Paulo: EDUSC. Belém: UFPA, 2005.

VELHO, Gilberto; DUARTE, Luiz F. (Org.). Juventude contemporânea: culturas, gostos e carreiras. Rio de Janeiro: 7Letras, 2010.

VIANNA, Hermano. Mundo Funk Carioca. Rio de Janeiro: Zahar, 1988

WELLER, Wivian. O Hip-hop nas cidades de São Paulo e Berlim: orientações coletivas e estratégias de superação do racismo de jovens negros e jovens de origem turca. In ENCONTRO ANUAL DA ANPOCS, 26. Caxambu. Anais... Caxambu: ANPOCS, 2002

A contribuição de Karl Mannheim para a pesquisa qualitativa: aspectos teóricos e metodológicos. Sociologias, Porto Alegre, v. 7, n 13, jan./jun., p. 260-300, 2005. Disponível em: www.scielo.br/pdf/soc/n13/23564.pdf. Acesso em: 3 dez. 2012.

Minha voz é tudo o que tenho: práxis estética e experiências discriminatórias de jovens neoros em São Paulo e de jovens turcos em Berlim. Belo Horizonte: UFMG, 2011.

Grupos de discussão na pesquisa com adolescentes e jovens: aportes teórico-metodológicos e análise de uma experiência com o método. Educ. Pesqui., São Paulo, v. 32, n. 2, p. 241-260, maio/ago., 2006. Disponível em: www.scielo.br/pdf/ep/v32n2/a03v32n2.pdf. Acesso em: 26 nov. 2012

WIRTH, L. O. urbanismo como modo de vida. In: VELHO, Otavio (Org.). O fenômeno urbano. Rio de Janeiro: Zahar, 1967. 


\section{DOCUMENTARY METHOD AND THE ANALYSIS OF GENERATIONAL ORIENTATION S OF YOUTH}

\author{
Breitner Luiz Tavares
}

Considering the theoretical-methodological diversity of studies about youths inside and outside Brazil, this paper provides a general presentation of the theoretical contribution of the documentary method developed since Karl Mannheim for qualitative research on Social Sciences. Thus we may observe the analytical potential of the method for studying the collective orientations encouraged by young people in order to establish a life style centered on youth culture as a preponderant factor for generational configuration. In empirical terms, this article proposes an approach to the problem with regard to the marginalization of young people in communities located in the outskirts of the Federal District, taking Ceilândia as an example. More precisely, the analytical cross-section is the life style of the hip-hop culture embraced by the youth of the Federal District, which is understood to be a mechanism for producing their collective orientations.

KEY wORDS: Documentary method. Collective orientations. Youth. Hip hop. Federal District.

\section{LA MÉTHODE DOCUMENTAIRE ET L'ANALYSE DES ORIENTATIONS GÉNÉRATIONNELLES DE LA JEUNESSE}

\author{
Breitner Luiz Tavares
}

Compte-tenu de la diversité théorique et méthodologique des études sur les jeunes au Brésil et à l'étranger, ce travail donne un aperçu de la contribution théorique de la méthode documentaire développée à partir de Karl Mannheim en matière de recherche qualitative en Sciences Sociales. Ainsi, il est possible d'observer le potentiel analytique de la méthode pour l'étude des orientations collectives promues par les jeunes, dans le sens de la construction d'un mode de vie d'une culture jeune, comme facteur prépondérant pour la configuration d'une génération. En termes empiriques, cet article propose une approche du problème concernant la marginalisation des jeunes des communautés situées dans les banlieues urbaines du District Fédéral, avec pour référence la région de Ceilândia. Plus précisément, l'échantillonnage destinéà l'analyse est celui du vécu de la culture hip-hop des jeunes du District Fédéral, considérée comme un mécanisme de production de leurs orientations collectives.

MotS-CLÉs: Méthode documentaire. Orientations collectives. Jeunesse. Hip hop. District Fédéral.

Breitner Luiz Tavares - Doutor em Sociologia pela Universidade de Brasília. Professor do Departamento de Saúde Coletiva da Universidade de Brasília. Integra o Núcleo de Pesquisa de Gênero Raça e Juventude (GERAJU), desenvolvendo pesquisas na área de sociologia da juventude. Suas mais recentes publicações, são: Na quebrada a parceria é mais forte: jovens vínculos afetivos e reconhecimento. São Paulo: Annablume; Brasília: Fundo de Apoio a Cultura do Distrito Federal, 2012. Sociologia da Juventude: da juventude desviante ao protagonismo jovem da Unesco Revista Soc. e Cul., Goiania, v. 15, n. 1, p. 181-191, jan./jun., 2012. 